\title{
Leguminosas de grano en México: variedades mejoradas de frijol y garbanzo desarrolladas por el INIFAP
}

\author{
José Luis Anaya-López ${ }^{1}$ \\ Francisco Javier Ibarra-Pérez ${ }^{2}$ \\ Franklin Gerardo Rodríguez-Cota ${ }^{3}$ \\ Pedro Francisco Ortega-Murrieta ${ }^{4}$ \\ Elizabeth Chiquito-Almanza ${ }^{1}$ \\ Jorge Alberto Acosta-Gallegos ${ }^{1 \S}$
}

${ }^{1}$ Campo Experimental Bajío-INIFAP. Carretera Celaya-San Miguel de Allende km 6.5, Celaya, Guanajuato. CP. 38110. ${ }^{2}$ Campo Experimental Cotaxtla-INIFAP. Carretera Federal Veracruz-Córdoba km 34.5, Medellín de Bravo, Veracruz. CP. 94270. ${ }^{3}$ Campo Experimental Valle del Fuerte-INIFAP. Carretera Internacional México-Nogales km 1609, Juan José Ríos, Sinaloa. CP. 81110. ${ }^{4}$ Campo Experimental Costa de Hermosillo-INIFAP. Pascual Encinas núm. 21, Col. La Manga, Hermosillo, Sonora. CP. 83220.

${ }^{\S}$ Autor para correspondencia: acosta.jorge@inifap.gob.mx.

\section{Resumen}

El frijol común, garbanzo, haba, lenteja y caupí están entre las leguminosas de grano más conocidas y consumidas en el mundo. En México el frijol (Phaseolus spp.) es el de mayor producción y consumo. De esas cinco especies, el Instituto Nacional de Investigaciones Forestales, Agrícolas y Pecuarias ha tenido una gran participación tanto en el desarrollo de variedades de frijol común como de garbanzo blanco de grano grande y de color café de grano pequeño. A nivel nacional algunas variedades de frijol se han convertido en un referente por su rendimiento y la calidad de su grano, como son 'Negro Jamapa', 'Mayocoba', 'Azufrado Higuera', 'Flor de Junio Marcela' y 'Pinto Saltillo'. En años recientes se han registrado variedades de los tipos con mayor demanda que están comenzando a utilizarse, algunas desarrolladas usando marcadores moleculares en el proceso de selección, tal es el caso de 'San Blas' y 'Rubí', resistentes al BCMV y BCMNV. En el caso del garbanzo, desde hace dos décadas la variedad 'Blanco Sinaloa-92' es la dominante en el mercado local y de exportación, y se cuenta con nuevas variedades de grano blanco para Sinaloa, Sonora y el Bajío. Con el objetivo de dar a conocer la contribución del INIFAP al mejoramiento de leguminosas de grano en México, en este ensayo se presenta la organización de las sedes de mejoramiento de frijol y garbanzo del INIFAP y las variedades que han desarrollado y registrado en los últimos 20 años.

Palabras clave: Cicer arietinum, Phaseolus vulgaris, mejoramiento genético, variedades.

Recibido: febrero de 2021

Aceptado: mayo de 2021 
Las legumbres son leguminosas que se cosechan para obtener su grano seco. El frijol común (Phaseolus vulgaris L.), garbanzo (Cicer arietinum L.), haba (Vicia faba L.), lenteja (Lens culinaris Medik.) y caupí (Vigna unguiculata L. Walp.) están entre las legumbres más conocidas y consumidas en el mundo (FAO, 2019). Leguminosas usadas como hortalizas o para la extracción de aceite, no se incluyen en este grupo.

En México, las legumbres son importantes desde una perspectiva agrícola, alimentaria y nutricional, por lo que es necesario promover su producción y consumo. En el país se consumen frijoles, habas, garbanzos y lentejas, y el frijol representa un caso particular debido a que se producen y consumen distintas especies y tipos de acuerdo con las preferencias de cada región.

La especie de mayor importancia económica y social, a la que se dirigen casi la totalidad de los esfuerzos de mejoramiento es $P$. vulgaris L. (frijol común), se estima que esta legumbre representa $36 \%$ de la ingesta diaria de proteínas de la población mexicana, aunque también existen otras especies como P. coccineus L. (frijol Ayocote o patol), P. lunatus L. (frijol lima), P. acutifolius A. Gray. (frijol tépari) y $P$. dumosus (frijol gordo) cuyo consumo se restringe a algunas localidades de México.

De acuerdo con información oficial, entre 2015-2019, México fue autosuficiente en la producción de garbanzo, del cual se exporta alrededor de 54\% de la cosecha nacional, no es así en el resto de las legumbres, ya que en este periodo se importaron en promedio $138646 \mathrm{t}$ de frijol, $1085 \mathrm{t}$ de haba y $75456 \mathrm{t}$ de lenteja y se exportaron $46554 \mathrm{t}$ de frijol, $26803 \mathrm{t}$ de lenteja y 466 t de haba (FAOSTAT, 2020). Con excepción del garbanzo, las legumbres se producen principalmente en temporal donde los rendimientos son limitados por factores de estrés ambiental.

Los principales estados productores de frijol son Zacatecas (33\%), Sinaloa (12\%), Durango (10\%) y Chihuahua (8\%), mientras que el garbanzo se produce principalmente en Sinaloa (42\%), Sonora (23\%), Jalisco (13\%) y Michoacán (9\%), el haba para grano, en Puebla (49\%), Veracruz (36\%) y Tlaxcala (9\%), la lenteja en Michoacán (90\%) y Guanajuato (10\%) y el caupí, principalmente, en Yucatán (93\%) (SIAP, 2020).

En México actualmente hay registradas en el Catálogo Nacional de Variedades Vegetales (CNVV) 100 variedades de frijol, 16 de garbanzo, seis de haba, y ninguna de lenteja ni caupí; de estas, el INIFAP tiene inscritas 80 variedades de frijol y 14 de garbanzo (SNICS, 2020a). Aunque el INIFAP realizó esfuerzos para el mejoramiento de lenteja, no se registró ninguna variedad. Las seis variedades de haba registradas en el CNVV fueron desarrolladas por el Instituto de Investigación y Capacitación Agropecuaria, Acuícola y Forestal del Estado de México (ICAMEX) (SNICS, 2020a). En México no se realiza mejoramiento genético de caupí y lenteja, la siembra se realiza principalmente con variedades criollas.

Debido a la importancia agrícola, alimentaria y nutricional que tienen las legumbres, en el presente ensayo es describir la organización de los programas de mejoramiento de frijol y garbanzo del INIFAP, y su contribución al mejoramiento de leguminosas de grano a través del desarrollo de variedades de frijol y garbanzo para México en los últimos 20 años. 


\section{Importancia de las legumbres}

En conjunto, en el periodo 2015-2019, el cultivo de legumbres en México tuvo un valor de producción de casi 17000 millones de pesos y ocupó alrededor de 1.78 millones de hectáreas, el equivalente a poco más de $12 \%$ del área destinada a los cultivos cíclicos en el país. La mayor superficie la ocupó el cultivo de frijol (90.7\%), seguido por garbanzo (6.8\%), haba (2\%), lenteja $(0.5 \%)$ y caupí $(0.02 \%)$ (SIAP, 2020). En ese mismo periodo, se produjo un promedio anual de 1.08 millones de toneladas de frijol; $250032 \mathrm{t}$ de garbanzo; $34426 \mathrm{t}$ de grano de haba; $6754 \mathrm{t}$ de lenteja y 1029 t de caupí (SIAP, 2020).

Las legumbres además de carbohidratos tienen un alto contenido de proteínas (15-30\%) y de aminoácidos esenciales como lisina y leucina (Wolf-Hall et al., 2017), por lo que son una fuente de proteína en regiones donde el acceso físico o económico a la carne y la leche es limitado, son bajas en grasa, ricas en fibra soluble y en compuestos bioactivos.

Su consumo está asociado con una menor mortalidad por cáncer (Papandreou et al., 2019), contribuyen a reducir el riesgo de desarrollar obesidad y diabetes tipo 2 (Moreno-Valdespino et al., 2020), y proveen beneficios a la salud cardiovascular (Blekkenhorst et al., 2018). Además, por su contenido de hierro, el consumo de frijol puede contribuir a erradicar la anemia que prevalece en áreas marginadas del país. Para los campesinos, son un cultivo importante, ya que son fáciles de almacenar después del secado y pueden venderlas o consumirlas a nivel familiar, lo que contribuye a mantener la seguridad alimentaria de sus hogares y genera estabilidad económica.

En comparación con los cereales, las legumbres tienen menor puntuación en la huella de carbono nutricional, un indicador que refleja la calidad nutricional a nivel de producto por unidad de impacto ambiental (Chaudhary et al., 2018) y en simbiosis con microorganismos del suelo, fijan nitrógeno atmosférico $\left(\mathrm{N}_{2}\right)$ incorporándolo a la planta y al suelo. Su cultivo puede contribuir a mitigar el cambio climático al reducir la dependencia de los fertilizantes sintéticos y de los gases de efecto invernadero, como el $\mathrm{CO}_{2}$ que se produce durante su fabricación y el $\mathrm{N}_{2} \mathrm{O}$ que se libera en los campos agrícolas por el uso de fertilizante nitrogenado. Se estima que los 241 millones de hectáreas (Mha) cultivadas con legumbres en el mundo fijan 28.4 Tg de nitrógeno anualmente.

\section{Antecedentes del mejoramiento genético de legumbres en México}

La investigación agrícola en México inició en la década de 1930 con la creación del Departamento de Campos Experimentales (DCE) dependientes de la Oficina General de Agricultura. En 1943, con el apoyo de la Fundación Rockefeller, se creó la Oficina de Estudios Especiales (OEE) como una unidad de investigación de la Secretaría de Agricultura y en 1947 el Instituto de Investigaciones Agrícolas (IIA), cuya finalidad era continuar los trabajos iniciados por el DCE.

Hasta 1961, el mejoramiento genético realizado por la OEE y el IIA dependió principalmente de variedades nativas. Con la desaparición de la OEE, en 1961 se creó el Instituto Nacional de Investigaciones Agrícolas (INIA), hoy Instituto Nacional de Investigaciones Forestales, Agrícolas y Pecuarias (INIFAP). Desde su creación, el INIA inició la recolección e introducción de recursos fitogenéticos de manera intensiva y en 1978, al serle transferidos los bancos de germoplasma de diferentes cultivos, se inició el Programa de Recursos Genéticos del INIFAP, que en 1995 disponía de 12652 accesiones de frijol (INIFAP, 1995). 
El mejoramiento genético del garbanzo inició en 1961. Las variedades mexicanas fueron desarrolladas a partir de germoplasma proveniente de la región mediterránea y asiática. El de grano blanco del mediterráneo provino de Francia, España e Italia, mientras que las asiáticas eran materiales de grano pequeño de color café de la India y Afganistán y en México éstas se destinan al consumo animal. En el noroeste el mejoramiento se enfocó a desarrollar variedades de alto rendimiento, tamaño de grano grande apto para la exportación, y con resistencia a pudriciones de la raíz, la cual se obtuvo mediante la cruza del garbanzo forrajero con variedades de garbanzo blanco. Se estima que $95 \%$ de la superficie nacional destinada al cultivo de garbanzo se siembra con variedades generadas en el país.

Actualmente, el INIFAP dispone de cinco sedes regionales donde se realiza el mejoramiento genético de frijol y dos sedes donde se realiza el de garbanzo. Estas sedes de mejoramiento se ubican en diferentes campos experimentales (CE) y desarrollan variedades acordes a la problemática y tipos de frijol y garbanzo que se producen en la región a la que pertenecen. El mejoramiento genético de frijol se realiza en los Campos Experimentales Valle del Guadiana, Bajío, Valle de México, Valle del Fuerte y Cotaxtla, mientras que el de garbanzo en los CE Valle del Culiacán y Costa de Hermosillo.

\section{Sedes de mejoramiento genético de frijol en el INIFAP}

Tres macrorregiones, que incluyen 22 entidades federativas, concentran $96 \%$ de la producción del frijol en México: la región del Altiplano semiárido-Bajío-Valles altos y las regiones costeras del Golfo y el Pacífico. Estas comparten parámetros ambientales y sistema de producción similares; sin embargo, difieren en importancia socioeconómica, tipos de grano que cultivan, volumen de producción y problemas agronómicos. Desde hace más de una década en el INIFAP no existe un Programa Nacional de mejoramiento genético de frijol, este se realiza en cinco campos experimentales de acuerdo con las demandas, problemática y necesidades de cada región.

El mejoramiento genético de frijol en el CE Valle del Guadiana (CEVAG), ubicado en Durango, se enfoca a generar las variedades para la región del altiplano semiárido, donde se produce frijol de los tipos pinto y negro brillante y en menor escala flor de mayo, flor de junio, bayos y garbancillo; esta región incluye a los estados de Zacatecas, Durango, Chihuahua, San Luis Potosí y el norte de Guanajuato. Las variedades desarrolladas por esta sede en los últimos 20 años, así como sus principales características se muestran en el Cuadro 1.

Cuadro 1. Variedades de frijol desarrolladas por el CE Valle del Guadiana entre 2000 y 2021.

\begin{tabular}{ccccc}
\hline Variedad & Año & Tipo & Cultivo & Atributos \\
\hline NOD 1 & 2018 & Negro Opaco & Riego & Alto potencial de rendimiento \\
PID 1 & 2018 & Pinto & Riego & Alto potencial de rendimiento \\
Dorado & 2012 & Pinto & Temporal & Grano de oscurecimiento lento \\
Pinto Bravo & 2010 & Pinto & Temporal & Grano de oscurecimiento lento \\
Pinto Coloso & 2010 & Pinto & Temporal & Grano de oscurecimiento lento \\
Pinto Centenario & 2010 & Pinto & Temporal & Grano de oscurecimiento lento \\
Pinto Libertad & 2010 & Pinto & Temporal & Grano de oscurecimiento lento \\
\hline
\end{tabular}




\begin{tabular}{ccccc}
\hline Variedad & Año & Tipo & Cultivo & Atributos \\
\hline Pinto Centauro & 2010 & Pinto & Temporal & Grano de Oscurecimiento lento \\
Pinto Durango & 2012 & Pinto & Temporal & Grano con propiedades funcionales \\
Negro Vizcaya & 2004 & Negro Brillante & Temporal & Roya \\
Flor de Mayo 2000 & 2001 & Flor de Mayo & Temporal & Tolerante a sequía \\
\hline
\end{tabular}

La región semiárida del altiplano a pesar de las condiciones ambientales limitantes es netamente productora de frijol en condiciones de temporal con excedentes de producción que se canalizan hacia otras entidades del país. Sin embargo, debido a los efectos negativos del cambio climático al disminuir la precipitación e incrementar la temperatura, se prevé menor productividad de frijol en esta región. Entre los problemas bióticos destacan las enfermedades foliares como roya (Uromyces appendiculatus var. appendiculatus), y antracnosis (Colletotrichum lindemuthianum), así como las pudriciones de raíz (Fusarium sp., Rhizoctonia solani, Macrophomina phaseolina). Las plagas más importantes son el picudo del ejote (Apion godmani y A. aurichalceum), conchuela (Epilachna varivestis) y gorgojos de almacén (Zabrotes subfasciatus y Acanthoscelides obtectus).

El área de influencia de la sede de mejoramiento del CE Bajío (CEBAJ), ubicado en Celaya, Guanajuato, incluye partes de la mesa central y de la faja volcánica transmexicana. Regiones colindantes que se caracterizan por una diversidad de nichos agrícolas que incluyen El Bajío, Altiplanos subhúmedos y semiáridos y Valles Altos. Esta región comprende parte de los estados de Guanajuato, Querétaro, Michoacán y Jalisco, donde el frijol como monocultivo se puede producir en dos épocas durante el año: bajo riego con siembras al final del invierno (enero-mayo) y otra de temporal y medio riego en el ciclo de verano (junio-octubre).

Se cultivan los tipos flor de mayo, flor de junio y negro brillante, en menor escala los tipos pinto, negro opaco y rosa de castilla. En esta subregión los problemas principales son la sequía intermitente, y las temperaturas altas, sobre todo en siembras de primavera bajo riego. Entre los problemas bióticos destacan la roya, antracnosis, bacteriosis común (Xanthomonas campestris pv. phaseoli) y de halo (Pseudomonas syringae pv. phaseoli), mancha angular (Phaeoisariopsis griseola) y pudriciones de raíz.

Las plagas más importantes, particularmente en las áreas de riego, son la chicharrita (Empoasca kraemeri), mosca blanca (Trialeurodes vaporariorum), trips (Thrips sp., Caliothrips phaseoli, Frankliniella occidentalis) y diabróticas (D. balteata), la gallina ciega (Phyllophaga spp.), picudo del ejote, conchuela y gorgojos de almacén.

Una característica de las variedades de frijol desarrolladas por el CEBAJ (Cuadro 2), en la que se presta especial atención y que tiene que ver con la adaptación a las condiciones erráticas del establecimiento del temporal de lluvias y con la fecha de siembra adecuada, es la reacción de la planta al fotoperíodo. Esta reacción es controlada por el gen $P p d P p d$, de fenotipo sensible o de día corto, mientras que el alelo $p p d$ ppd da la reacción neutral. 
Cuadro 2. Variedades de frijol desarrolladas por el CE Bajío entre 2000 y 2021.

\begin{tabular}{ccccc}
\hline Variedad $^{\mathrm{a}}$ & Año & Tipo & Cultivo $^{\mathrm{b}}$ & Atributos $^{\mathrm{c}}$ \\
\hline San Blas & 2018 & Negro Opaco & $\mathrm{T}, \mathrm{HR}, \mathrm{R}$ BCMV y BCMNV (genes II + bc-3), neutral \\
Salinas & 2018 & Pinto & $\mathrm{T}$ & Grano de oscurecimiento lento, de día corto \\
Granada & 2013 & Rojo & R T & BCMV y roya, de día corto \\
Rarámuri & 2012 & Pinto & R T & Grano de oscurecimiento lento, neutral \\
San Rafael & 2012 & Pinto & R T & Grano de oscurecimiento lento, neutral \\
Dalia & 2012 & Flor de Junio & R T & BCMV y roya, de día corto \\
Junio León & 2012 & Flor de Junio & R T & BCMV, alto rendimiento, de día corto \\
FM Dolores & 2010 & Flor de Mayo & T & BCMV y roya, neutral al fotoperiodo \\
FM Eugenia & 2010 & Flor de Mayo & R y T & BCMV y roya, neutral al fotoperiodo \\
Ng Guanajuato & 2008 & Negro Opaco & R T & Resistente a roya \\
FM Anita $^{\mathrm{d}}$ & 2003 & Flor de Mayo & R y T & BCMV \\
Coranay $^{\mathrm{e}}$ & 2010 & Negro Opaco & T HR R & Para zona costera de Nayarit \\
Costenay $^{\mathrm{e}}$ & 2010 & Negro Opaco & T HR R & Para zona costera de Nayarit \\
Frijozac N-101 $^{\mathrm{f}}$ & 2006 & Negro Opaco & T & Alto potencial de rendimiento \\
\hline
\end{tabular}

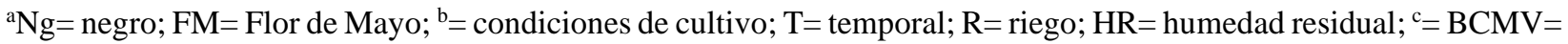
virus del mosaico común del frijol; $\mathrm{BCMNV}=$ virus necrótico del mosaico común del frijol; ${ }^{\mathrm{d}}=$ dominio público; ${ }^{\mathrm{e}}=$ desarrollada en el CE Santiago Ixcuintla; ${ }^{\mathrm{f}}=$ desarrollada en el CE Zacatecas.

La sede de mejoramiento del CE Valle de México (CEVAMEX), ubicado en Texcoco, Estado de México, es el más antiguo del país y su principal área de influencia incluye los valles altos y altiplano sub-húmedo de los estados de Puebla, Hidalgo, Tlaxcala y el Estado de México. El frijol se produce en su mayor parte en condiciones de temporal.

En esta región el cultivo es afectado por diversas enfermedades como la roya (Uromyces appendiculatus var. phaseoli), antracnosis, mancha blanca de la hoja (Pseudocercosporella albida), y bacteriosis (López-Frías, 1991), así como por plagas como conchuela, picudo del ejote y el gorgojo pardo (Acanthoscelides obtectus). Entre los factores abióticos destacan las temperaturas bajas y la sequía intermitente. Las variedades desarrolladas por esta sede en los últimos 20 años, así como sus principales características se muestran en el Cuadro 3.

Cuadro 3. Variedades frijol desarrolladas por el CE Valle de México entre 2000 y 2021.

\begin{tabular}{ccccc}
\hline Variedad & Año & Tipo & Cultivo $^{\text {a }}$ & Atributos \\
\hline Luciomex & 2020 & Ejotero & R T & Para Valles Altos y altiplano subhúmedo \\
Xicuco-10 & 2020 & & $\mathrm{~T}$ & Para Valles Altos y altiplano subhúmedo \\
Mayomex & 2019 & Flor de Mayo & $\mathrm{T}$ & Para Valles Altos y altiplano subhúmedo \\
Azufradomex & 2019 & Azufrado & $\mathrm{R} \mathrm{T}$ & Planta de hábito determinado \\
Huitel-143 & 2019 & Franciscano & Temporal & Para Valles Altos y altiplano subhúmedo \\
Azufradoro & 2014 & Azufrado & $\mathrm{R} \mathrm{T}$ & Planta de hábito determinado \\
\hline
\end{tabular}




\begin{tabular}{ccccc}
\hline Variedad & Año & Tipo & Cultivo $^{\mathrm{a}}$ & Atributos \\
\hline Altiplanomex & 2014 & Negro Opaco & $\mathrm{T}$ & Para Valles Altos y altiplano subhúmedo \\
Primavera 28 & 2011 & Negro Opaco & $\mathrm{T}$ & Para Valles Altos y altiplano subhúmedo \\
Albicampo & 2010 & Negro Opaco & $\mathrm{T}$ & Para Valles Altos y altiplano subhúmedo \\
Bayo Azteca & 2010 & Bayito & $\mathrm{T}$ & Resistente al picudo del ejote \\
Pinto Saltillo & 2004 & Pinto & $\mathrm{T}$ & Grano de oscurecimiento lento tolerante a \\
& & & & Tequía \\
Negro Otomí & 2000 & Negro Brillante & $\mathrm{T}$ & Tolerante a enfermedades
\end{tabular}

${ }^{\mathrm{a}}=$ condiciones de cultivo; $\mathrm{T}=$ temporal $\mathrm{R}=$ riego; $\mathrm{HR}=$ humedad residual.

La sede del CE Valle del Fuerte (CEVAF), en Los Mochis, Sin., es responsable del mejoramiento en la región costera del Pacífico, que comprende las áreas de producción del occidente del país Sinaloa, Sonora y Nayarit, donde se siembran principalmente los tipos azufrado peruano de tamaño grande (Sinaloa), pinto moteado (Sonora) y negro opaco (en más de 50\% de la superficie cultivada en Nayarit) y en pequeñas superficies del sur de Sinaloa.

En esta región destacan las enfermedades virales, principalmente el mosaico dorado amarillo del frijol, provocado por el virus del mosaico dorado amarillo del frijol (BGYMV), el mosaico común del frijol provocados por el virus del mosaico común del frijol (BCMV) y virus necrótico del mosaico común del frijol (BCMNV) y la raíz negra (BCMNV), las enfermedades foliares como roya, bacteriosis común, el moho blanco (Sclerotinia sclerotorium) y las pudriciones de raíz, los insectos con mayor incidencia son la mosca blanca (Bemisia tabaci), que actúa como transmisor de enfermedades, doradillas (Diabrotica spp.) y chicharritas, que causan daños severos en las primeras etapas de desarrollo de la planta. Entre los factores abióticos está la sequía terminal en las áreas de humedad residual y las altas temperaturas.

Históricamente, en esta sede se han desarrollado variedades de colores claros, pintos y negros, dos de ellas, Azufrado Pimono-78 (Mayocoba) y Azufrado Higuera desarrolladas en 1978 y 1995, respectivamente, aún tiene un gran impacto en la superficie de frijol sembrada en México, particularmente Azufrado Higuera. Azufrado Pimono-78 (Mayocoba) fue la primera variedad de grano grande tipo Peruano mientras que Azufrado Higuera se convirtió prácticamente en una nueva clase de frijol de muy alta aceptación por los comercializadores.

En los últimos 20 años en esta sede se desarrollaron las variedades 'Azufrasin', 'Janasa' y 'Aluyori', las dos primeras de tipo azufrado y la ultima de tipo alubia grande, todas ellas para condiciones de riego, con resistencia a roya y tolerancia a BGYMV. En el CE Cotaxtla (CECOT), ubicado en Medellín de Bravo, Veracruz, en colaboración con el CE Centro de Chiapas, se desarrollan variedades de grano negro de alto potencial de rendimiento, amplia adaptación, resistencia o tolerancia a las enfermedades y periodos de sequía terminal, su área de influencia extiende al sureste del país, a los estados de Chiapas, Quintana Roo, Yucatán, Campeche, Tabasco, Veracruz y la parte tropical de San Luis Potosí y del sur de Tamaulipas (Cuadro 4). Se cultiva principalmente frijol negro opaco. 
Cuadro 4. Variedades de frijol desarrolladas por el CE Cotaxtla entre 2000 y 2021.

\begin{tabular}{|c|c|c|c|c|}
\hline Variedad $^{\mathrm{a}}$ & Año & Tipo & Cultivo $^{\mathrm{b}}$ & Atributos ${ }^{\mathrm{c}}$ \\
\hline Rubí & 2019 & $\begin{array}{l}\text { Negro Opaco } \\
\text { pequeño }\end{array}$ & $\mathrm{T}, \mathrm{HR}, \mathrm{R}$ & BGYMV y BCMV (genes $I I+b c-3$ ), precoz \\
\hline Verdín & 2014 & Negro Opaco & $\mathrm{T}, \mathrm{HR}, \mathrm{R}$ & $\begin{array}{l}\text { BGYMV, BCMV (genes II y } b g m-1 \text { ), precoz, } \\
\text { resistente a sequía terminal }\end{array}$ \\
\hline Sangre Maya & 2013 & Rojo & T HR R & BGYMV, BCMV (genes II y $b g m-1$ ), \\
\hline Frailescano & 2013 & $\begin{array}{l}\text { Negro semi } \\
\text { Brillante }\end{array}$ & T HR R & BGYMV, BCMV (genes $I I$ y $b g m-1$ ), \\
\hline Ng Tacaná & 2012 & Negro Opaco & T R HR & BGYMV, BCMV (genes $I I$ y $b g m-1$ ) \\
\hline $\mathrm{Ng}$ Comapa & 2010 & Negro Opaco & $\mathrm{T}, \mathrm{HR}$ & $\begin{array}{c}\text { Mancha angular, roya; alto rendimiento y } \\
\text { amplia adaptación }\end{array}$ \\
\hline Rojo INIFAP & 2008 & Rojo & & Roya, BGYMV \\
\hline Ng Papaloapan & 2006 & $\begin{array}{l}\text { Negro opaco } \\
\text { pequeño }\end{array}$ & $\mathrm{T}, \mathrm{HR}, \mathrm{R}$ & $\begin{array}{c}\text { Roya, mancha angular; tolerancia a suelos } \\
\text { ácidos }\end{array}$ \\
\hline Ng Grijalva & 2003 & Negro Opaco & $\mathrm{T}, \mathrm{HR}, \mathrm{R}$ & $\begin{array}{c}\text { BGYMV; precoz, planta erecta, tolerancia a } \\
\text { suelos ácidos }\end{array}$ \\
\hline Ng Tropical & 2002 & Negro Opaco & $\mathrm{T}, \mathrm{HR}, \mathrm{R}$ & Roya, BGYMV, BCMV \\
\hline Ng Medellín & 2001 & Negro Opaco & $\mathrm{T}, \mathrm{HR}, \mathrm{R}$ & Mancha angular; amplia adaptación \\
\hline
\end{tabular}

${ }^{\mathrm{a}} \mathrm{Ng}=$ negro; ${ }^{\mathrm{b}}=$ condiciones de cultivo; $\mathrm{T}=$ temporal; $\mathrm{R}=$ riego; $\mathrm{HR}=$ humedad residual $;{ }^{\mathrm{c}}=\mathrm{BCMV}=$ virus del mosaico común del frijol; BCMNV= virus necrótico del mosaico común del frijol; BGYMV= virus del mosaico dorado amarillo del frijol. En el caso de BCMV y BCMNV se tiene resistencia, en el de BGYMV tolerancia.

En los altos de Chiapas también se siembran variedades nativas de $P$. coccineus y $P$. dumosus y en el Soconusco $P$. acutifolius. En esta región destacan enfermedades como el mosaico dorado amarillo del frijol, el mosaico común, roya, mancha angular, antracnosis y pudriciones de raíz (López-Salinas et al., 2006), plagas como la mosca blanca, doradillas y chicharritas, un molusco conocido como 'babosa', que causa severos daños en las primeras etapas de desarrollo. Entre los factores abióticos los problemas son la sequía terminal en las siembras de humedad residual (López-Salinas et al., 2008) y los suelos ácidos de baja fertilidad (Zetina-Lezama et al., 2002).

\section{Métodos de mejoramiento genético de frijol}

El método de mejoramiento más utilizado en el programa de mejoramiento de frijol es el de pedigrí, con algunas modificaciones. En ocasiones se utiliza el retrocruzamiento y el método masal. El mejoramiento se inicia con la cruza de progenitores con los rasgos de interés complementarios. Para acelerar el proceso se utilizan progenitores con características de grano similar, pero complementarios en relación a los genes de resistencia que poseen. Por su parte, las actividades tradicionales de mejoramiento genético en campo e invernadero, que incluyen la identificación de progenitores, cruzas complementarias, selección y evaluación bajo un esquema combinado genealógico-masal (Fehr, 1987).

Una ventaja, en el caso de la sede del CEBAJ, es que se pueden establecer dos ciclos de cultivo por año, lo que permite un rápido avance en el proceso de selección y desarrollo de líneas. El proceso inicial de avance de generaciones y selección se realiza en dos siembras consecutivas 
dentro del ciclo primavera-verano, una en condiciones de riego que se establece en febrero y otra en condiciones de temporal que se establece en julio. Posteriormente, en generaciones avanzadas se realizan ensayos preliminares de rendimiento y las líneas sobresalientes se incorporan a ensayos que se establecen en diferentes localidades de la región.

\section{Selección asistida de frijol por marcadores moleculares}

Desde hace una década en el CEBAJ se cuenta con laboratorios de marcadores moleculares. En este se establecen los protocolos para realizar selección asistida contra enfermedades, principalmente antracnosis, mosaico común y raíz negra (BCMV y BCMNV), selección del fenotipo de oscurecimiento lento de la testa y se desarrollan herramientas moleculares para detectar a los principales virus que infectan al frijol en México (Chiquito-Almanza et al., 2017).

El laboratorio de marcadores moleculares presta servicios a las sedes de mejoramiento que lo requieran. Además, se realizan rutinariamente aislamientos para la identificación de razas de antracnosis y su multiplicación para utilizarse en inoculaciones artificiales bajo condiciones controladas. Para antracnosis, el gen de resistencia que más se ha utilizado en el programa es el $C o 4^{2}$, mientras que, para el mosaico común y la raíz negra, los genes $I I$ y $b c-3$ y se realizan inoculaciones con la cepa BCMNV NL3 en condiciones controladas.

El proceso para seleccionar materiales de tipo Pinto con oscurecimiento lento de la testa del grano, consiste en el uso del MM asociado al gen $s d s d$ ligado al oscurecimiento lento del grano (Felicetti et al., 2012) y la exposición del grano a luz ultravioleta por 72 h (Junk-Knievel et al., 2007). La fuente de oscurecimiento lento utilizada ha sido la variedad Pinto Saltillo.

En los últimos años se ha trabajado en incorporar el gen $s d s d$ de los materiales pintos a los tipos Flor de Mayo y Junio, pero ni el marcador ni el proceso de selección basado en la exposición a la luz ultravioleta han funcionado. Así, la selección se basa en la conservación del color después de nueve meses de almacenamiento en condiciones naturales. Hasta ahora, el uso de las herramientas moleculares se ha enfocado a sistemas de selección basados en electroforesis en geles de agarosa y marcadores moleculares (MM) de tipo SCAR (región amplificada de secuencia caracterizada) y CAPS (secuencias polimórficas amplificadas y cortadas).

Estos se utilizan en la fase final de evaluación de líneas sobresalientes, para lo cual, se confirma la presencia de los MM en un grupo de 300 plantas individuales de cada línea y se multiplica la semilla de 200 progenies uniformes en función a la presencia del MM para obtener la semilla original. Esto ha disminuido los costos asociados al uso de los MM y seleccionar de manera precisa las líneas de interés.

\section{Variedades mejoradas de frijol registradas y liberadas por el INIFAP}

En el CNVV actualmente hay registradas 100 variedades de frijol, 80 de las cuales fueron desarrolladas e inscritas por el INIFAP. Es importante destacar que los esfuerzos de mejoramiento se han enfocado al desarrollo de variedades arbustivas para sistemas de monocultivo.

Debido a que en México los productores no adquieren semilla de manera regular, sino que usan grano para sus siembras, es difícil conocer cuáles son las variedades que se están cultivando. En este sentido, los datos de producción de semilla calificada brindan un panorama de las principales 
variedades en uso. De acuerdo con el SNICS durante los años agrícolas 2018 a 2020 se produjo semilla de frijol de los tipos azufrado ('Azufrado Higuera', 'Azufrado Regional 87', 'Azufrado Noroeste', 'Janasa' y 'Reyna'), pinto ('Pinto Saltillo', 'Pinto Libertad'), negro opaco ('Negro Jamapa', 'Negro Comapa', 'Verdín', 'San Blas', 'Negro Chapingo', 'Frijozac N-101'), negro brillante ('Negro Brillante', 'Bruján'), flor de junio ('Flor de Junio Marcela', 'Dalia', 'Junio León'), blanco ('Aluyori’) y cacahuate ('Rayado Rojo') (SNICS, 2020b). Con excepción de las variedades 'Reyna', 'Negro Chapingo', 'Negro Brillante', 'Bruján' y 'Rayado Rojo', el resto fueron desarrolladas por el INIFAP. A nivel nacional, las variedades que se están multiplicando en mayores volúmenes son 'Pinto Saltillo' y 'Azufrado Higuera'.

\section{Sedes y métodos de mejoramiento genético de garbanzo en el INIFAP}

Existen dos sedes de mejoramiento de garbanzo, uno en el CE Valle del Culiacán, en Culiacán, Sinaloa, y otro en el CE Costa de Hermosillo en Hermosillo, Sonora, que trabajan en estrecha colaboración con la sede del CE Bajío. Entre los principales factores abióticos que afectan el garbanzo destacan la sequía terminal cuando solo se usa un riego de presiembra o se establece con humedad residual y las temperaturas extremas, estrés por calor o las heladas que afectan las siembras de noviembre en el ciclo otoño-invierno y que en caso extremo causan la muerte de la planta.

Los factores bióticos más importantes son la alta incidencia de hongos del suelo, siendo el principal Fusarium oxysporum y en menor frecuencia F. solani, Rhizoctonia solani, Sclerotium rolfsii, Macrophomina phaseolina y Pythium sp. que reducen el rendimiento hasta en $80 \%$, en condiciones de alta humedad ambiental hay incidencia de enfermedades foliares, en el Sur de Sonora y Sinaloa son el mildiu (Peronospora ciceris), moho gris (Botrytis cinerea) (Fierro-Corrales et al., 2015), el tizón por alternaría (Alternaria alternata) y ocasionalmente se presenta roya (Uromyces cicerisarietini), moho blanco (Sclerotinia sclerotiorum) y tizón (Ramírez-Arredondo et al., 2017).

Dentro de las plagas más frecuentes destacan el gusano soldado (Spodoptera exigua) y el gusano del fruto (Heliothis sp.), cuya incidencia se favorece con alta humedad relativa y ocasionan reducción en el rendimiento y calidad del grano (Padilla-Valenzuela et al., 2008).

En el mejoramiento genético de garbanzo se utiliza principalmente el método genealógico con selección masal e individual alternada y el uso de parcelas infestadas con los patógenos que causan las pudriciones de raíz. Las líneas superiores se incluyen en ensayos preliminares de rendimiento en los campos sedes y las líneas superiores conforman un ensayo nacional.

\section{Variedades mejoradas de garbanzo registradas y liberadas por el INIFAP}

En los últimos 25 años el instituto ha registrado y puesto a disposición de los productores, 14 variedades mejoradas (Cuadro 5), entre ellas 'Blanco Sinaloa-92' ocupa más de 90\% de la superficie cultivada con garbanzo. Hace unos años se registraron dos cultivares, de grano blancocremoso grande 'Blanoro' y 'Jumbo 2010', con resistencia a pudriciones de raíz (Fusarium spp.), que cubren los requerimientos de calidad del mercado de exportación y dos variedades de grano pequeño de color, El Patrón y Pénjamo. 
Cuadro 5. Variedades mejoradas de garbanzo desarrolladas por el INIFAP.

\begin{tabular}{|c|c|c|c|c|}
\hline Variedad & Año & Grano & Planta & Resistencia/característica ${ }^{b}$ \\
\hline Blanco Sinaloa-92 & 1992 & Blanco cremoso & Semierecta & PR, amplia adaptación \\
\hline Costa $2004^{a}$ & 2004 & Blanco cremoso & Erecta & PR, tardío \\
\hline Lerma & 2001 & Café claro & Abierta & PR \\
\hline San Antonio 05 & 2005 & Café oscuro & Abierta & PR \\
\hline Tequi Blanco-98 & 1999 & Blanco cremoso & Semierecta & PR \\
\hline Jumbo $2010^{\mathrm{a}}$ & 2010 & Blanco cremoso & Semierecta & PR, amplia adaptación \\
\hline Blanoro & 2011 & Blanco cremoso & Semierecta & PR \\
\hline El Patrón ${ }^{\mathrm{a}}$ & 2015 & Café claro & Semierecta & PR, amplia adaptación \\
\hline Pénjamo $^{\mathrm{a}}$ & 2015 & Café claro & Erecta & PR \\
\hline Mazocahui $^{\mathrm{a}}$ & 2017 & Blanco cremoso & Semierecta & PR, amplia adaptación \\
\hline Blancoson & 2017 & Blanco cremoso & Semierecta & PR \\
\hline Nubia & 2018 & Blanco cremoso & Semiabierta & PR \\
\hline Sinalomex-2018 a & 2018 & Blanco cremoso & Semierecta & PR \\
\hline Combo- $743^{\mathrm{a}}$ & 2018 & Blanco cremoso & Semierecta & PR, amplia adaptación \\
\hline
\end{tabular}

${ }^{\mathrm{a}}=$ apta para cosecha directa; ${ }^{\mathrm{b}}=\mathrm{PR}=$ pudriciones de raíz.

Recientemente, se registraron cinco nuevas variedades de grano blanco grande: Sinalomex, Combo 743, Blancoson, Mazocahui y Nubia, las dos primeras en Sinaloa, las siguientes en Sonora y la última en Guanajuato. De acuerdo con el SNICS durante los años agrícolas 2018 a 2020 se produjo semilla calificada de garbanzo de las variedades 'Blanco Sinaloa-92', 'BlancoSon', 'Jumbo 2010', 'Lerma', 'Mazocahui', 'SG Criollo' y 'SG Porquero' (SNICS, 2020b). De estas, la variedad que se está multiplicando en mayor volumen es 'Blanco Sinaloa-92' y con excepción SG Criollo' y 'SG Porquero' todas las variedades fueron desarrolladas por el INIFAP.

\section{Conclusiones}

El INIFAP es la institución en México con mayor impacto y contribución a la producción de leguminosas de grano a través del desarrollo de variedades de frijol y garbanzo para las distintas regiones y tipos que demanda el mercado nacional; algunas variedades de frijol como 'Negro Jamapa', 'Mayocoba', ‘Azufrado Higuera', 'Flor de Junio Marcela' y 'Pinto Saltillo' y la variedad de garbanzo 'Blanco Sinaloa-92' son un referente para el mercado nacional e internacional.

Con excepción de 'Pinto Saltillo', todas estas fueron desarrolladas hace más de 20 años. Otras variedades desarrolladas recientemente de los tipos con mayor demanda están comenzando a utilizarse, tal es el caso de las variedades de frijol 'Janasa', 'Pinto Libertad', 'Negro Comapa', 'Verdín', 'San Blas', 'Frijozac N-101' 'Dalia', 'Aluyori', y las de garbanzo 'BlancoSon', 'Jumbo 2010', 'Lerma' y 'Mazocahui'. La inclusión de marcadores y otras herramientas moleculares en el programa de mejoramiento de frijol ha contribuido a incrementar la precisión y a reducir el tiempo para el desarrollo de nuevas variedades. 


\section{Literatura citada}

Blekkenhorst, L. C.; Sim, M.; Bondonno, C. P.; Bondonno, N. P.; Ward, N. C.; Prince, R. L.; Devine, A.; Lewis, J. R. and Hodgson, J. M. 2018. Cardiovascular health benefits of specific vegetable types: a narrative review. Nutrients 10(5):1-24.

Chaudhary, A.; Marinangeli, C. P. F.; Tremorin, D. and Mathys, A. 2018. Nutritional combined greenhouse gas life cycle analysis for incorporating canadian yellow pea into cereal-based food products. Nutrients 10(4):1-18.

Chiquito-Almanza, E.; Acosta-Gallegos, J. A.; García-Álvarez, N. C.; Garrido-Ramírez, E. R.; Montero-Tavera, V.; Guevara-Olvera, L. and Anaya-López, J. L. 2017. Simultaneous detection of both RNA and DNA viruses infecting dry bean and occurrence of mixed infections by BGYMV, BCMV and BCMNV in the Central-west region of Mexico. Viruses 9(4):1-13.

FAOSTAT. 2020. Comercio. Cultivos y productos de ganadería. http://www.fao.org/faostat/es/ \#data/TP.

Felicetti, E.; Song, Q.; Jia, G.; Cregan, P.; Bett, K. E. and Miklas, P. N. 2012. Simple sequence repeats linked with slow darkening trait in pinto bean discovered by single nucleotide polymorphism assay and whole genome sequencing. Crop Sci. 52(4):1600-1608.

Fehr, W. 1987. Principles of cultivar development. Theory and technique. New York, MacMillan. $536 \mathrm{p}$.

Fierro-Corrales, D.; Apodaca-Sánchez, M. A.; Quintero-Benítez, J. A.; Leyva-Mir, S. G.; FloresSánchez, J. L. and Tovar-Pedraza, J. M. 2015. Morphological characterization and histopathology of Peronospora ciceris in chickpea (Cicer arietinum L.) leaves and seeds. Rev. Chapingo Ser Hortic. 21(1):81-92.

INIFAP. 1995. Instituto Nacional de Investigaciones Forestales Agrícolas y Pecuarias. México: informe nacional para la conferencia técnica internacional de la FAO sobre los recursos fitogenéticos. Leipzig, 1996. 49 p.

Junk-Knievel, D. C.; Vandenberg A. and Bett, K. E. 2007. An accelerated postharvest seed-coat darkening protocol for pinto beans grown across different environments. Crop Sci. 47(2):694-700.

López-Frías, L. C. 1991. Definición de prioridades de investigación fitopatológica para la zona templada del altiplano central de México. Agric. Téc. Méx. 17(1):17-54.

López-Salinas, E.; Tosquy-Valle, O. H.; Villar-Sánchez, B.; Becerra-Leor, E. N.; Ugalde-Acosta, F. J. y Cumpián-Gutiérrez, J. 2006. Adaptabilidad de genotipos de frijol resistentes a enfermedades y a suelos ácidos. Rev. Fitotec. Mex. 29(1):33-39.

López-Salinas, E.; Tosquy-Valle, O. H.; Ugalde-Acosta, F. J. y Acosta-Gallegos, J. A. 2008. Rendimiento y tolerancia a sequía de genotipos de frijol negro en el estado de Veracruz. Rev. Fitotec. Mex. 31(3):35-39.

Moreno-Valdespino, C. A.; Luna-Vital, D.; Camacho-Ruiz, R. M. and Mojica, L. 2020. Bioactive proteins and phytochemicals from legumes: mechanisms of action preventing obesity and type-2 diabetes. Food Res. Int. 130(1):108905.

FAO. 2019. Organización de las Naciones Unidas para la Alimentación y la Agricultura. Las legumbres protagonizan una alianza emblemática. http://www.fao.org/news/story/es/item/ 1254924/icode/. 
Padilla-Valenzuela, I.; Valenzuela-Valenzuela, R. I.; Armenta-Castro, C. M.; Salinas-Pérez, R. A. y Sánchez-Sánchez, E. 2008. Comportamiento agronómico de genotipos de garbanzo en siembra tardía en el Valle del Mayo, Sonora, México. Rev. Fitotec. Mex. 31(1):43-43.

Papandreou, C.; Becerra-Tomás, N.; Bulló, M.; Martínez-González, M. A.; Corella, D.; Estruch, R.; Ros, E.; Arós, F.; Schröder, F. and Fito, M. 2019. Legume comsumption and risk of all-cause, cardiovascular, and cancer mortality in the PREDIMED study. Clin Nutr. 38(1):348-356.

Ramírez-Arredondo, J. A.; Padilla-Valenzuela, I. y Castillo-Torres, N. 2017. Control químico de las enfermedades foliares del garbanzo en el sur de Sonora. INIFAP-Campo Experimental Norman E. Borlaug. Sitio Experimental Valle del Mayo, Cd. Obregón, Sonora, México. Folleto técnico núm. 103. 24 p.

SIAP. 2020. Servicio de Información Agroalimentaria y Pesquera. Datos abiertos. Estadística de Producción Agrícola. http://infosiap.siap.gob.mx/gobmx/datosAbiertos.php.

SNICS. 2020a. Servicio Nacional de Inspección y Certificación de Semillas. Catálogo Nacional de Variedades Vegetales. https://datastudio.google.com/u/0/reporting/5b7206ba-e190-48fe9696-73523bfccf58/page/itBWB.

SNICS. 2020b. Servicio Nacional de Inspección y Certificación de Semillas. Boletín de semilla calificada. https://www.gob.mx/snics/acciones-y-programas/boletin-de-semilla-calificada.

Wolf-Hall, C.; Hillen, C. and Robinson, J. G. 2017. Composition, nutritional value, and health benefits of pulses. Cereal Chem. 94(1):11-31.

Zetina-Lezama, R.; Pastrana-Aponte, L.; Romero-Mora, J. y Jiménez-Chong, J. A. 2002. Manejo de suelos ácidos para la región tropical húmeda de México. Instituto Nacional de Investigaciones Forestales, Agrícolas y Pecuarias-Centro de Investigación Regional del Golfo Centro-Campos Experimentales Papaloapan y Huimanguillo. Veracruz, México. Libro técnico núm. 10. 170 p. 